\title{
The ternary IGF complex influences postnatal bone acquisition and the skeletal response to intermittent parathyroid hormone
}

\author{
Shoshana Yakar*, Mary L Bouxsein ${ }^{1 *}$, Ernesto Canalis ${ }^{2}$, Hui Sun, \\ Vaida Glatt ${ }^{1}$, Caren Gundberg ${ }^{3}$, Pinchas Cohen ${ }^{4}$, David Hwang ${ }^{4}$, \\ Yves Boisclair ${ }^{5}$, Derek LeRoith and Clifford J Rosen ${ }^{6,7}$ \\ National Institute of Diabetes, Digestive and Kidney Diseases, Bethesda, Maryland, USA \\ ${ }^{1}$ Beth Israel Deaconess Medical Center, Harvard Medical School, Boston, Massachusetts, USA \\ ${ }^{2}$ St Francis Hospital and Medical Center, Hartford, Connecticut, USA \\ ${ }^{3}$ Yale University School of Medicine, New Haven, Connecticut, USA \\ ${ }^{4}$ Mattel Hospital for Children, Los Angeles California, USA \\ ${ }^{5}$ The Department of Animal Science, Cornell University, Ithaca, New York, USA \\ ${ }^{6}$ The Jackson Laboratory, Bar Harbor, Maine, USA \\ ${ }^{7}$ Maine Center for Osteoporosis Research and Education, St Joseph Hospital, Maine, USA \\ (Requests for offprints should be addressed to C J Rosen at Maine Center for Osteoporosis Research and Education, St Joseph Hospital, 900 Broadway, \\ Bangor, Maine 04401, USA; Email: rofe@aol.com) \\ *(S Yakar and M L Bouxsein contributed equally to the study)
}

\begin{abstract}
The role of circulating IGF-I in skeletal acquisition and the anabolic response to PTH is not well understood. We generated IGF-I-deficient mice by gene deletions of IGF ternary complex components including: (1) liver-specific deletion of the IGF-I gene (LID), (2) global deletion of the acid-labile (ALS) gene (ALSKO), and (3) both liver IGF-I and ALS inactivated genes (LA). Twelve-week-old male control (CTL), LID, ALSKO, and LA mice were treated with vehicle $(\mathrm{VEH})$ or human $\mathrm{PTH}(1-34)$ for 4 weeks. VEH-treated IGF-I-deficient mice (i.e. LID, ALSKO and LA mice) exhibited reduced cortical crosssectional area $(P=0 \cdot 001)$ compared with CTL mice; in contrast, femoral trabecular bone volume fractions (BV/TV) of the IGF-I-deficient mice were consistently greater than CTL $(P<0 \cdot 01)$. ALSKO mice exhibited markedly reduced osteoblast number and surface $(P<0 \cdot 05)$, as well as mineral apposition rate compared
\end{abstract}

with other IGF-I-deficient and CTL mice. Adherent bone marrow stromal cells, cultured in $\beta$-glycerol phosphate and ascorbic acid, showed no strain differences in secreted IGF-I. In response to PTH, there were both compartment- and strain-specific effects. Cortical bone area was increased by PTH in CTL and ALSKO mice, but not in LID or LA mice. In the trabecular compartment, PTH increased femoral and vertebral BV/TV in LID, but not in ALSKO or LA mice. In conclusion, we demonstrated that the presentation of IGF-I as a circulating complex is essential for skeletal remodeling and the anabolic response to $\mathrm{PTH}$. We postulate that the ternary complex itself, rather than IGF-I alone, influences bone acquisition in a compartment-specific manner (i.e. cortical vs trabecular bone).

Journal of Endocrinology (2006) 189, 289-299

\section{Introduction}

Insulin-like growth factor-I (IGF-I) is a ubiquitous polypeptide that serves as a regulator of cell growth and function. IGF-I can exert its biological effects using two distinct routes: the endocrine route, i.e. via circulating IGF-I, and the autocrine/paracrine route, which represents locally produced IGF-I (Salmon \& Daughaday 1957, LeRoith et al. 2001). The endocrine form of IGF-I originates mainly from liver and its synthesis is growth hormone $(\mathrm{GH})$-dependent. In the circulation, IGFs are bound in a ternary complex of high molecular weight $\sim 150 \mathrm{kDa}$ with a family of high affinity IGF-binding proteins (IGFBPs) and the acid labile subunit (ALS) (Leong et al. 1992). Once the ternary complex, which is found primarily in the vascular system, dissociates, the binary complexes of IGFBP-IGFs are removed from the circulation and IGF-I reaches target tissues where it interacts with cell surface receptors. In the skeleton, IGF-I is important for osteoblast differentiation and mineralization, and can stimulate osteoclast recruitment (Mochizuki et al. 1992, Zhao et al. 2000, Rubin et al. 2002, Zhang et al. 2002). Serum IGF-I levels correlate positively with bone mineral density (BMD) and 
negatively with fracture risk in humans (Langlois et al. 1998, Gamero et al. 2000). However, the role of serum IGF-I and its ternary complex as an endocrine modulator of skeletal compartments (i.e. cortical and trabecular) remains controversial.

To study the endocrine and autocrine/paracrine roles of IGF-I in growth and development, we previously generated liver-specific IGF-I gene deleted (LID) mice. In the LID mouse, total circulating IGF-I levels were lowered by $75 \%$ and $\mathrm{GH}$ levels were correspondingly elevated, approximately fourfold (Yakar et al. 1999). Importantly, IGF-I and IGF-II mRNA expression in bone were not altered (Yakar et al. 2002a, 2002b). Growth, as assessed by changes in body weight and body length, did not differ significantly between control (CTL) and LID mice. Skeletal analysis of bones from LID mice using peripheral quantitative computerized tomography ( $\mathrm{pQCT}$ ) revealed a mild reduction in bone size and a marked reduction in femoral volumetric bone density (vBMD) (Yakar et al. $2002 a, 2002 b$ ). A similar skeletal phenotype was noted following ALS gene inactivation (ALSKO), in which a $65 \%$ reduction in circulating IGF-I levels but no increase in $\mathrm{GH}$ secretion was observed. A double gene inactivation mouse model of LID/ALSKO (LA) caused an even further reduction in circulating IGF-I levels of $85 \%-90 \%$ and a reciprocal increase in GH levels of about 15-fold (Yakar et al. 2002a). In contrast to the LID mice, the LA mice showed early post-natal growth retardation, as assessed by body length and femoral length, as well as a significant reduction in femoral vBMD (Yakar et al. 2002a, 2002b). Interestingly, Igf1 null mice also exhibit a cortical phenotype similar to LA mice, but have increased trabecular bone volume fractions (BV/TV) (Bikle et al. 2001, 2002).

Daily administration of parathyroid hormone (human $\mathrm{PTH}(1-34))$ increases bone mass, reduces fracture risk, and is approved for the treatment of severe postmenopausal osteoporosis (Neer et al. 2001). PTH principally targets osteoblasts, enhancing osteoblast function, and reducing osteoblast apoptosis (Jilka et al. 1999). Recent studies suggest that not all individuals treated with PTH respond in the same manner, implying that local or systemic factors may contribute to the heterogeneity in skeletal responsiveness to this agent (Sellmeyer et al. 2004). In vitro and in vivo studies have shown that a number of osteoblast growth factors are activated by intermittent PTH (Hurley et al. 1999, Calvi et al. 2003, Qin et al. 2003). In vitro, PTH induces IGF-I expression and secretion in osteoblasts (McCarthy et al. 1989). Additionally, antibodies to IGF-I block PTH-stimulated collagen synthesis in fetal rat calvarial cultures (Canalis et al. 1989). Furthermore, intermittent PTH did not stimulate bone formation or increase bone turnover in Igf1 null mice (Bikle et al. 2002). Despite these data, the role of the endocrine IGF regulatory system in mediating the anabolic effects of PTH remains unclear.

To understand the role of the ternary IGF-I complex in bone modeling and the anabolic response to $\mathrm{PTH}$, we studied three strains of IGF-I-deficient mice (i.e. subsequently defined as LID, ALSKO, and LA) as well as CTL mice of the same mixed background with and without PTH treatment. The results of these experiments show that the presentation of IGF-I in the circulation as a ternary complex is essential both for postnatal bone acquisition and for the full anabolic response to PTH.

\section{Materials and Methods}

\section{Animal husbandry and experimental design}

The generation and genotyping of control (CTL), liverspecific IGF-I deficient (LID), ALSKO and LA mice have been described previously (Yakar et al. 2002a). These mice were generated on a mixed genetic background of $\mathrm{FVB} / \mathrm{N}, \mathrm{C} 57 \mathrm{Bl} / 6 \mathrm{~J}$ and 129Sv. Briefly, ALSKO mice were crossed for 6 generations on $\mathrm{C} 57 \mathrm{Bl} / 6 \mathrm{~J}$ and than crossed with the LID mice to generate the double gene disrupted mice LID+ALSKO (LA). Crossing of males and females from the F2 generation gave rise to four different genotypes within the same litter: (a) control mice, which are homozygous for the Igf-1 floxed allele, carry an intact Als gene $(\mathrm{ALS}+/+)$, and do not carry the Alb-cre transgene; (b) LID mice, which are homozygous for the Igf-1 floxed allele, carry the Alb-cre transgene and carry an intact Als gene $(\mathrm{ALS}+/+)$; (c) ALSKO mice, which are homozygous for the Igf- 1 floxed allele, have two Als null alleles (ALS - / - ) and do not carry the Alb-cre transgene; (d) LID \pm ALSKO mice (LA), which are homozygous for the Igf-1 floxed allele, carry the Alb-cre transgene and have two ALS null alleles (ALS $-/-$ ). Mice that were heterozygous for any of the alleles als or floxed Igf-1 were not included in the study. No difference was observed between mice that carried one or two copies of the Cre transgene. The above four genotypes represent the mice that were used throughout this study.

To study the effects of intermittent PTH treatment on bone remodeling, twelve-week-old male mice were injected subcutaneously 5 days a week with $50 \mu \mathrm{g} / \mathrm{kg} /$ day human $\mathrm{PTH}(1-34)$ (Bachem, Torrance, CA, USA) or vehicle ( $2 \%$ normal mouse serum in saline) over a course of 4 weeks. Calcein $(15 \mathrm{mg} / \mathrm{kg})$ was injected intraperitoneally 7 and 2 days before death. Mice were killed at the end of week 4, serum was collected, and the L5 vertebral body and femur were assessed by micro-computed tomography $(\mu \mathrm{CT})$ and histomorphometry. All procedures were approved by the Animal Care and Use Committee of the National Institute of Diabetes and Digestive and Kidney Diseases, National Institute of Health, Bethesda, MD, USA.

\section{Measurement of biochemical parameters}

IGF-I Serum IGF-I was measured using an RIA with a polyclonal human anti-IGF-I antibody that has previously 
been validated in mice (Rosen et al. 2004). Briefly, serum samples were treated with an acid-ethanol preparation removing IGF binding proteins. IGF-II was then added to remove residual or partially proteolyzed IGFBPs, and the remaining sample was then assayed using a double antibody method (Alpco, Windham, NH, USA). The sensitivity of the assay is $0.3 \mathrm{ng} / \mathrm{ml}$ and there is no cross reactivity with IGF-II. The interassay coefficient of variation was $4.6 \%$, and the intra-assay coefficient of variation was $2 \cdot 3 \%$. Known standards are placed in each run, and pooled mouse serum from B6 mice at 16 weeks of age is used as another control for assay variation. IGF-I was also measured in the conditioned media (CM) of bone marrow stromal cells after 14 days -7 days in $10 \%$ fetal calf serum and $\alpha M E M$, and 7 days of $\beta$-glycerol phosphate and ascorbic acid. The same RIA that was used for serum was employed in the CM.

IGFBP-2 Serum IGFBP-2 was measured using an RIA with a polyclonal human antibody to IGFBP-2 (DSL, Webster, TX, USA) validated previously for mouse serum (Rosen et al. 2004). The interassay coefficient of variation is $9 \cdot 6 \%$ using $\mathrm{C} 57 \mathrm{Bl} / 6 \mathrm{~J}$ control mouse sera from $16-$ week-old males. The sensitivity of the assay is $5 \mathrm{ng} / \mathrm{ml}$ and there is no cross-reactivity with IGFBP-1 or IGFBP-3.

Growth hormone (GH) Serum concentrations of GH were determined using an RIA kit with a sensitivity of $0.02 \mathrm{ng} / \mathrm{ml}$ (National Hormone and Pituitary Program, Harbor-UCLA Medical Center, Torrance, CA, USA).

Mouse IGFBP-3 and ALS ELISA assays Mouse recombinant IGFBP-3 and ALS standards, rat anti-mouse IGFBP-3 and ALS monoclonal antibodies, and biotinylated goat anti-mouse IGFBP-3 and ALS antibodies were purchased from R\&D Systems (Minneapolis, MN, USA). Microtiter plates were obtained from Nalge Nunc International (Rochester, NY, USA). Streptavidinhorseradish peroxidase conjugate, o-phenylenediamine dihydrochloride and hydrogen peroxide substrate were purchased from Pierce (Rockford, IL, USA). Microtiter plates (96-well) were coated with capture antibodies at $0.5 \mathrm{~g} /$ well in $100 \mathrm{ml}$ phosphate-buffered saline (PBS) (137 mM NaCl, $2.7 \mathrm{mM} \mathrm{KCl,} 8.1 \mathrm{mM} \mathrm{Na}_{2} \mathrm{HPO}_{4}$, and $1.5 \mathrm{mM} \mathrm{KH_{2 }} \mathrm{PO}_{4}, \mathrm{pH} 7 \cdot 4$ ). The plate was incubated overnight at room temperature on a shaker. The antibody-coated plate was washed three times with $300 \mathrm{ml} /$ well of wash buffer (PBS containing 0.05\% Tween-20) followed by the addition of $300 \mathrm{ml}$ blocking buffer (PBS containing 5\% Tween-20, 5\% sucrose, and $0.05 \%$ sodium azide) to each well and incubation for an additional $1 \mathrm{~h}$. After washing three times with wash buffer, the plates were used for IGFBP-3 or ALS assays as appropriate. Recombinant mouse IGFBP-3 or ALS standard was diluted in sample dilution buffer in concentrations ranging from 0 to $25 \mathrm{ng} / \mathrm{ml}$ for IGFBP-3 and from 0 to $250 \mathrm{ng} / \mathrm{ml}$ for ALS. The mouse serum samples were pre-diluted 100 - to 400 -fold prior to assay. Standards, controls, or diluted samples $(100 \mathrm{ml})$ were added to appropriate wells and incubated at room temperature for $2 \mathrm{~h}$ on a shaker. The wells were then washed three times with wash buffer followed by the addition of detection antibody (20 ng/well in $100 \mathrm{ml}$ PBS containing 5\% Tween-20 and 2\% normal goat serum) and incubated at room temperature for $2 \mathrm{~h}$. The wells were washed three times again and $100 \mathrm{ml}$ streptavidin-horseradish peroxidase conjugate was added to each well and incubated for $20 \mathrm{~min}$ at room temperature. After washing four times with wash buffer, $100 \mathrm{ml}$ o-phenylenediamine $(1 \mathrm{mg} / \mathrm{ml}$ in hydrogen peroxide substrate) was added to each well and incubated for an additional $20 \mathrm{~min}$. The reaction was stopped by the addition of $50 \mathrm{ml} 1 \mathrm{M}$ sulfuric acid and the absorbance was determined at $490 \mathrm{~nm}$ with a plate reader (Molecular Design, Sunnyvale, CA, USA). The IGFBP-3 assay has a sensitivity of $0.2 \mathrm{ng} / \mathrm{ml}$. There is no crossreactivity with mouse IGFBP-1 or -2 , human IGFBP-1, $-2,-3$ or -4 , mouse IGF-I or -II or human IGF-I or -II (all test substances at $100 \mathrm{ng} / \mathrm{ml}$ ). The intra-assay and interassay coefficients of variation were less than $6 \%$ in the range from 1 to $6 \mathrm{ng} / \mathrm{ml}$ and recovery was 89 to $104 \%$ in the assay range from 2 to $10 \mathrm{ng} / \mathrm{ml}$. The mouse ALS assay has a sensitivity of $1 \cdot 0 \mathrm{ng} / \mathrm{ml}$. There is no cross-reactivity with mouse IGFBP-1, -2 or -3 , human IGFBP-1, $-2,-3$ or -4 , mouse IGF-I or -II or human ALS, IGF-I or -II. The intra-assay and interassay coefficients of variation were less than $10 \%$ in the range from 10 to $60 \mathrm{ng} / \mathrm{ml}$ and recovery was 94 to $102 \%$ in the range from 15 to $85 \mathrm{ng} / \mathrm{ml}$.

Osteocalcin Osteocalcin was measured in $10 \mu \mathrm{l}$ serum by a standard equilibrium radioimmunoassay using specific goat anti-mouse osteocalcin antibody and authentic purified mouse osteocalcin as standard and tracer (Rosen et al. 2005). Quality control was routinely monitored in each assay by assaying two known samples that fall in the low and high concentration regions of the standard curves (Rosen et al. 2005).

\section{Bone morphology by $\mu \mathrm{CT}$}

Micro-computed tomography $(\mu \mathrm{CT}, \mu \mathrm{CT} 40$; Scanco Medical AG, Basserdorf, Switzerland) was used to assess trabecular bone volume fraction and microarchitecture in the excised 5th lumbar vertebral body and distal femoral metaphysis, and cortical bone geometry at the midfemoral diaphysis, as previously described (Rosen et al. 2005). Morphometric variables were computed from the binarized images using direct, three-dimensional techniques that do not rely on any prior assumptions about the underlying structure (Hildebrand \& Ruegsegger 1997, Laib et al. 1997). For trabecular bone regions, we assessed the bone volume fraction (BV/TV, \%), trabecular 
Table 1 Serum parameters for control (CTL), LID, ALSKO and LA mice after 4 weeks of vehicle (VEH) or PTH treatment

\begin{tabular}{|c|c|c|c|c|c|c|c|c|}
\hline & \multicolumn{2}{|c|}{ Control $(C T L)$} & \multicolumn{2}{|l|}{ LID } & \multicolumn{2}{|l|}{ ALSKO } & \multicolumn{2}{|l|}{ LA } \\
\hline & $\begin{array}{l}\text { VEH } \\
(n=10)\end{array}$ & $\begin{array}{l}\text { PTH } \\
(n=8)\end{array}$ & $\begin{array}{l}\mathrm{VEH} \\
(n=9)\end{array}$ & $\begin{array}{l}\text { PTH } \\
(n=9)\end{array}$ & $\begin{array}{l}\text { VEH } \\
(n=13)\end{array}$ & $\begin{array}{l}\text { PTH } \\
(n=10)\end{array}$ & $\begin{array}{l}\text { VEH } \\
(n=9)\end{array}$ & $\begin{array}{l}\text { PTH } \\
(n=11)\end{array}$ \\
\hline IGFBP-2 (ng/ml) & $411 \pm 106$ & $511 \pm 129$ & $315 \pm 19^{b}$ & $339 \pm 48$ & $264 \pm 40^{\mathrm{b}}$ & $230 \pm 25$ & $219 \pm 24^{b}$ & $214 \pm 26$ \\
\hline IGFBP-3 (ng/ml) & $294 \pm 66$ & $354 \pm 93$ & $160 \pm 7^{\mathrm{a}}$ & $126 \pm 9$ & $6 \pm 1^{\mathrm{a}}$ & $4 \cdot 5 \pm 1 \cdot 3$ & $17 \pm 1^{\mathrm{a}}$ & $18 \pm 1$ \\
\hline $\mathrm{ALS}(\mathrm{ng} / \mathrm{ml})$ & $824 \pm 68$ & NM & $5718 \pm 307^{a}$ & NM & $0^{\mathrm{a}}$ & NM & $0^{\mathrm{a}}$ & NM \\
\hline
\end{tabular}

${ }^{a} P<0.0001$ vs CTL within VEH; ${ }^{b} P=0.001$ vs CTL within VEH; ${ }^{c} P<0.05$ vs CTL within VEH; ${ }^{d} P<0.001$ vs VEH within genotype; ${ }^{\text {e }} P<0 \cdot 01$ vs VEH within genotype. NM, not measured

thickness (TbTh, $\mu \mathrm{m})$, trabecular number $\left(\mathrm{TbN}, \mathrm{mm}^{-1}\right.$ ), and trabecular separation (TbSp, $\mu \mathrm{m})$. For cortical bone at the femoral midshaft, we measured the average total cross-sectional area inside the periosteal envelope (TA, $\mathrm{mm}^{2}$ ), the cortical bone and medullary area within this same envelope (BA, $\mathrm{mm}^{2}$ and $\mathrm{MA}, \mathrm{mm}^{2}$ respectively), the bone area fraction (BA/TA, \%), and the average cortical thickness (CortTh, $\mu \mathrm{m}$ ).

\section{Bone histomorphometric analysis}

Femurs were dissected, fixed in 70\% ethanol, dehydrated and embedded undecalcified in methyl methacrylate. Longitudinal sections, $5 \mu \mathrm{m}$ thick, were cut on a Microm microtome (Microm, Richards-Allan Scientific, Kalamazoo, MI, USA) and stained with Toluidine Blue. Static parameters of bone formation and resorption were measured at a standardized site in the distal femoral metaphysis using an OsteoMeasure morphometry system (Osteometrics, Atlanta, GA, USA). Relative trabecular bone volume (BV/TV), osteoid surface (OS/BS, \%), eroded surface (ES/BS, \%), osteoblast or osteoclast number per bone perimeter ( $\mathrm{NOb} / \mathrm{BPm}, \mathrm{NOc} / \mathrm{BPm})$ and osteoblast or osteoclast number per total area $(\mathrm{NOb} /$ Tar, NOc/Tar) were measured. For dynamic histomorphometry, mineralizing surface per bone surface (MS/BS, \%) and mineral apposition rate (MAR, $\mu \mathrm{m} /$ day) were measured in unstained $10 \mu \mathrm{m}$ sections under ultraviolet light, using a B-2A set long pass filter consisting of an excitation filter ranging from 450 to 490 nanometers $(\mathrm{nm})$, a barrier filter at $515 \mathrm{~nm}$, and a dichroic mirror at $500 \mathrm{~nm}$. Bone formation rate per bone surface (BFR, $\mu \mathrm{m}^{3} / \mu \mathrm{m}^{2} /$ day) was calculated. The terminology and units used are those recommended by the Histomorphometry Nomenclature Committee of the American Society for Bone and Mineral Research (Parfitt et al. 1987).

\section{Statistical analysis}

Standard descriptive statistics were computed for all variables. Underlying differences in serum biochemistry, bone microarchitecture and histomorphometric variables between different mutants were evaluated within vehicle (VEH)-treated animals by ANOVA, followed when appropriate by post-hoc testing using Fisher's Least Squares Protected Difference test. The effect of PTH on these variables was assessed first by two-factor ANOVA, with genotype (CTL, LID, ALSKO and LA) and treatment (PTH or VEH) as independent variables. The effect of PTH within each genotype was assessed by unpaired $t$-test between VEH- and PTH-treated mice. In all cases, tests were two-tailed, and significance was set at $P<0 \cdot 05$, unless otherwise noted. Data are reported as means \pm S.E.M.

\section{Results}

Serum IGF ternary complex components are altered in IGF-I-deficient mice

To assess how circulating IGF-I presentation affects skeletal parameters, we determined serum levels of IGF-I, IGFBP-2, IGFBP-3, ALS and GH in the various IGF-Ideficient mice (Table 1). Evaluating the vehicle-treated groups, we confirmed that both serum IGF-I and IGFBP-2 concentrations were significantly decreased in ALSKO, LID and LA compared with CTL mice $(P<0 \cdot 001$ for all, Table 1$)$. A reduction in serum IGF-I concentrations in LID mice led to a significant reduction in IGFBP-3 levels, possibly due to degradation (data not shown), and when the ALS gene was inactivated (i.e. ALSKO and LA mice), IGFBP-3 concentrations were reduced to almost undetectable levels (Table 1). In the LID and LA mice, the low levels of IGF-I in serum are insufficient to inhibit growth hormone $(\mathrm{GH})$ secretion, and therefore spontaneous GH levels were two- to threefold higher in LA and LID mice compared with CTL $(P<0 \cdot 05$ for both). In contrast, ALSKO mice did not exhibit an increase in GH despite a significant reduction in serum IGF-I (Table 1). GH largely controls ALS levels. Therefore, in the LID mice where GH levels were elevated, there was a sevenfold increase in serum ALS compared with CTL mice $(P<0 \cdot 0001)$. As expected, in ALSKO and LA mice the ALS was undetectable. Serum 
A) Mid-Fem Total Area $\left(\mathrm{cm}^{2}\right)$

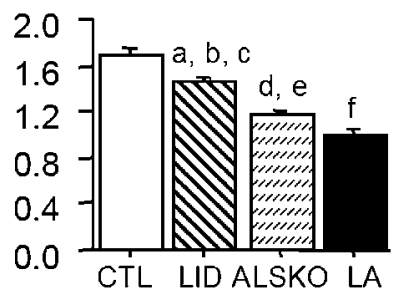

D) Vert BV/TV (\%)

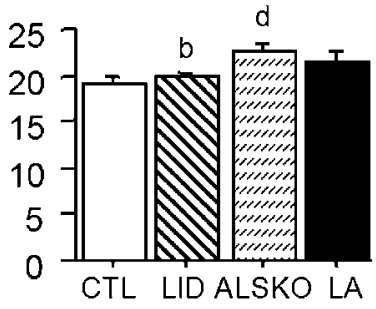

B) Mid-Fem Bone Area $\left(\mathrm{cm}^{2}\right)$

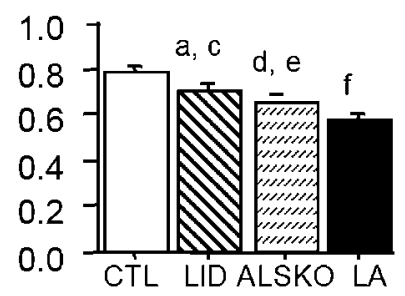

E) Vert $\operatorname{TbN}\left(\mathrm{mm}^{-1}\right)$

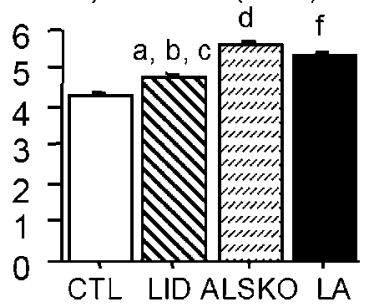

C) Mid-Fem BA/TA (\%)

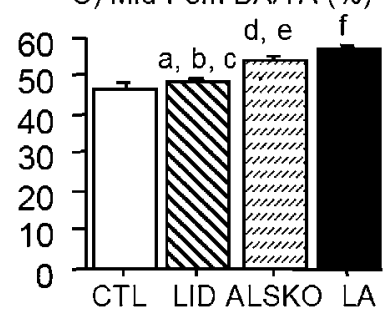

F) Vert TbTh $(\mu \mathrm{m})$

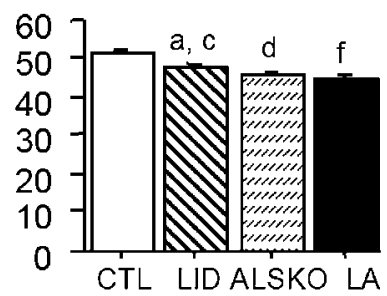

Figure 1 Cortical and trabecular bone microarchitecture, assessed by micro-computed tomography, in VEH-treated control (CTL), LID, ALSKO and LA mice. (A) Mid-femoral total cross-sectional area $\left(\mathrm{cm}^{2}\right)$, (B) mid-femoral cortical bone area $\left(\mathrm{cm}^{2}\right)$, (C) mid-femoral cortical bone area fraction (BA/TA, \%), (D) vertebral trabecular BV/TV (\%), (E) vertebral trabecular number $\left(\mathrm{TbN}, \mathrm{mm}^{-1}\right)$, and (F) vertebral trabecular thickness $(\mathrm{TbTh}, \mu \mathrm{m})$. Symbols represent statistically significant differences $(P<0 \cdot 05)$ between (a) LID vs CTL, (b) LID vs ALSKO, (c) LID vs LA, (d) ALSKO vs CTL, (e) ALSKO vs LA and (f) LA vs CTL.

osteocalcin, a bone-specific protein secreted by osteoblasts, was not altered in the LID mice as compared with controls; however, it was markedly depressed in ALSKO mice $(P<0.001$ for ALSKO vs CTL, Table 1$)$. LA mice displayed intermediate levels of osteocalcin, which may have been related to the secondary increase in GH levels.

\section{Alterations in the IGF ternary complex influence skeletal growth and remodeling}

We found striking differences in the cortical and trabecular skeleton in VEH-treated IGF-I-deficient mice (Figs 1 and 2). Mid-femoral total cross-sectional area was markedly decreased when circulating IGF-I concentrations were low (CTL $>$ LID $>$ ALSKO $>$ LA; $P<0 \cdot 001$ for all), and cortical BA/TA displayed a reciprocal increase $(P<0.0001$ for all $)$. Cortical thickness was greatest in ALSKO $(208 \pm 3 \mu \mathrm{m})$ and lowest in LID $(194 \pm 4 \mu \mathrm{m}$, $P=0.02$ vs ALSKO), but otherwise did not differ significantly between genotypes.

Interestingly, a different pattern was observed for trabecular bone structure (Figs 1 and 2). In the vertebral body, trabecular bone volume fraction by $\mu \mathrm{CT}$ was higher in ALSKO and LA compared with CTL $(P=0.002$ and $P=0.06$ respectively). Trabecular number was greater in ALSKO and LA than LID $(P<0 \cdot 003)$, but all groups were greater than CTL $(P<0 \cdot 007$ for all). Trabecular thickness was lower in IGF-I-deficient mice than in CTL mice $(0 \cdot 018<P<0 \cdot 001)$. Trabecular bone parameters at the distal femur, assessed by $\mu \mathrm{CT}$, followed the same pattern as those in the vertebral body (data not shown, see Fig. 2).

To determine how bone modeling is affected by changes in the GH/IGF-I system, we performed histomorphometric measurements of the secondary spongiosa in the distal femur (Table 2). The most striking observation was the marked suppression of osteoblast number $(P<0.02$ vs all other groups), osteoblast surface $(P<0.001$ vs all other groups), and osteoid surface $(P=0.02$ vs CTL $)$ in ALSKO mice. Mineralizing surface and bone formation rates were higher in LID than ALSKO mice ( $P=0.01$ for both), but otherwise did not differ among groups. The mineral apposition rate was significantly lower in the ALSKO mice compared with the other IGF-I-deficient groups $(P<0 \cdot 05)$ and marginally lower than CTL mice. Notable was the consistent increase in osteoclastic parameters in LA mice, reflected by greater eroded surfaces $(P=0 \cdot 01)$ and osteoclast surface/bone surface $(P=0 \cdot 05)$ compared with CTL mice. There was also a trend for more osteoclasts per bone perimeter in LA compared with CTL mice $(P=0 \cdot 08)$.

Although we had previously found no expression differences in IGF-I mRNA from the femorae of the various mouse groups, we wanted to exclude differences in IGF-I secretion as a possible cause for the distinct skeletal phenotypes of the IGF-I-deficient mice (Yakar et al. 2002a). We cultured adherent marrow stromal cells after one week of $10 \%$ FCS and $\alpha$ MEM, followed by one week of osteoblast differentiation media. We found no 

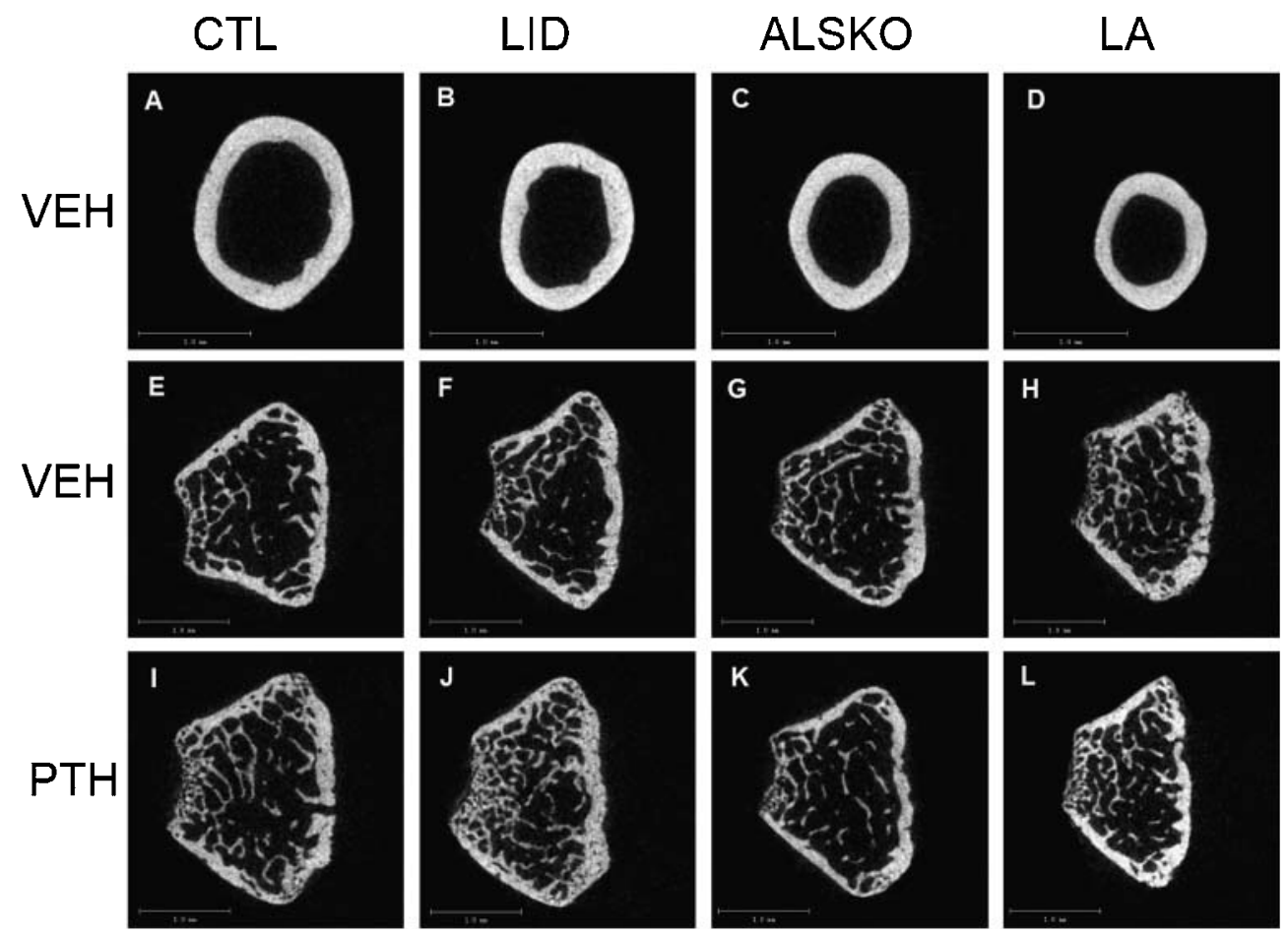

Figure 2 Representative microcomputed tomography images of the femoral midshaft in VEH-treated mice (upper panel), and the distal femoral metaphysis in both VEH- and PTH-treated mice (middle and lower panels).

differences in secreted IGF-I among CTL, LID, ALSKO or LA mice (data not shown). Taken together, these data suggest that in IGF-I-deficient mice without a compensatory increase in GH (i.e. ALSKO mice) or changes in local production of IGF-I, there is significantly decreased osteoblast function.

\section{Alterations in the IGF ternary complex influence skeletal responsiveness to intermittent $P T H$}

PTH treatment did not affect circulatory concentrations of the IGF complex (i.e. IGF-I, IGFBP-2 or IGFBP-3) (Table 1). In contrast, osteocalcin concentrations increased following PTH in all groups, reaching significance in PTH-treated LID and LA mice (+99\% vs VEH, $P<0 \cdot 001$ and $+50 \%$ vs VEH, $P<0 \cdot 01$ respectively). The effects of PTH on cortical and trabecular bone microarchitecture differed by genotype. Cortical bone anabolic responses, assessed at the mid-femur, were strongest in CTL and ALSKO mice, in whom there were significant gains in cortical bone area $(+13.7 \% \quad P=0.042$ and $+9 \cdot 3 \%$, $P=0.027$ respectively) and cortical thickness $(+6 \cdot 4 \%$, $P=0.09$ and $+6 \cdot 0 \%, P=0.018$ respectively) (Fig. 3).

In contrast to the effect of PTH on cortical bone, trabecular bone volume fraction increased most dramatically and consistently in LID mice $(+26 \%$ vs VEH at vertebrae, $P=0.002$ and $+50 \%$ vs VEH at the distal femur,
$P=0.003$ ) (Figs 2 and 3). Trabecular number and thickness were also consistently higher in PTH-treated LID compared with VEH. In contrast, trabecular bone volume was unchanged in ALSKO at both skeletal sites and unchanged in LA at the vertebrae, but declined significantly at the distal femur ( $-27 \%$ vs VEH, $P=0 \cdot 05$ ) (Figs 2 and 3). In summary, the $\mu \mathrm{CT}$ data show that in the trabecular bone compartment, LID mice had a consistent anabolic response, whereas ALSKO and LA mice either had no change or a catabolic response to intermittent PTH treatment.

The effects of PTH on trabecular architecture assessed by histomorphometry were similar to those detected by $\mu \mathrm{CT}$, with a marked increase in BV/TV in LID, no change in CTL and ALSKO, and a significant decline in LA mice (Table 2 and Fig. 2). Interestingly, despite variable changes in trabecular bone volume among the different genotypes, PTH treatment led to consistent increases in osteoblast number and bone formation rate. The effects of PTH on osteoclasts varied significantly by genotype $(P<0 \cdot 007)$. CTL mice responded to PTH with an increase in osteoclast number and eroded surfaces $(0 \cdot 06<P<0 \cdot 01)$. LID and ALSKO showed a tendency for increases in osteoclastic parameters, whereas LA did not (Table 2). Taken together, these data suggest that, even though the mechanisms responsible for PTH anabolic actions on the skeleton are not clearly defined, changes in 


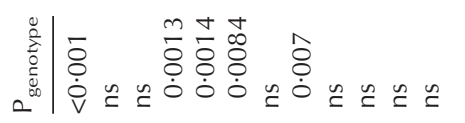

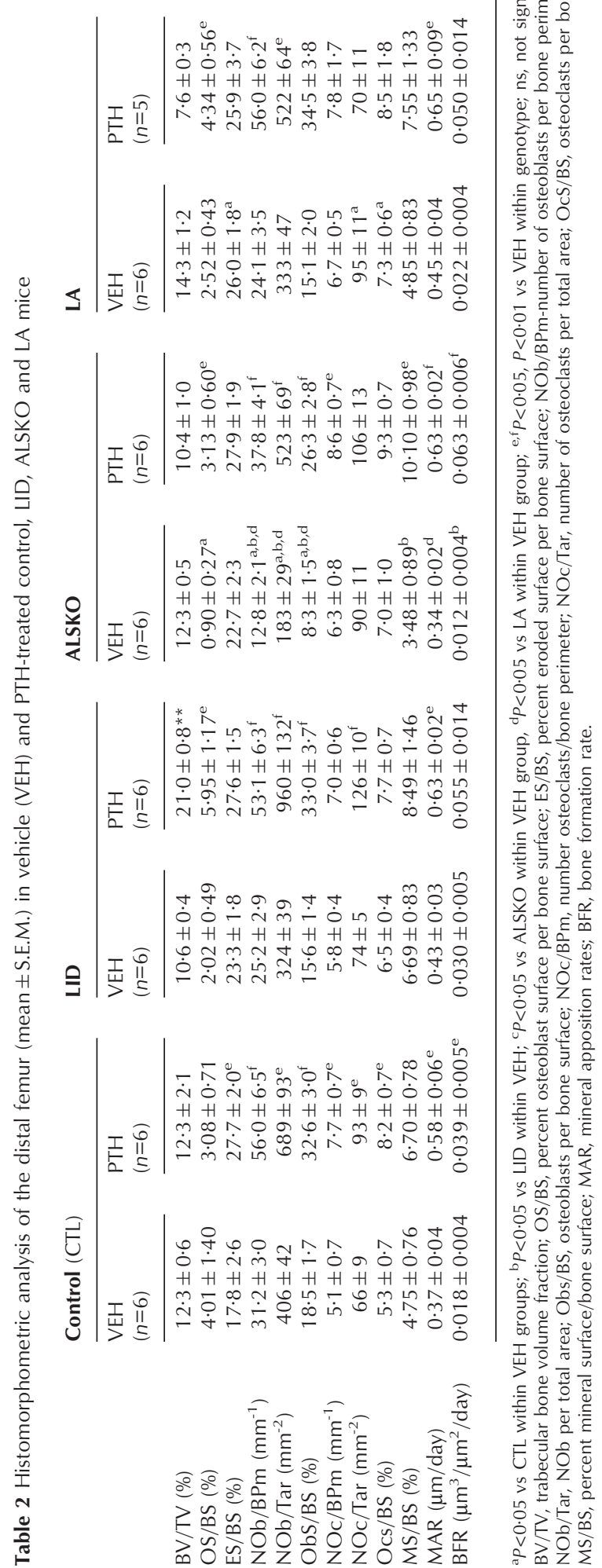




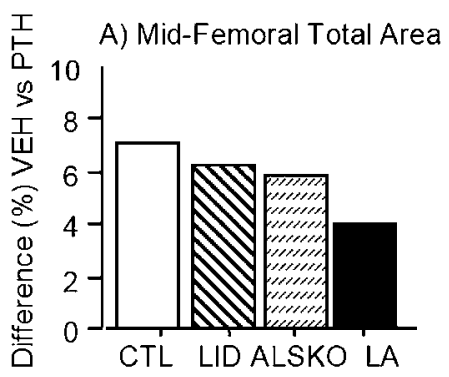

B) Mid-Femoral Bone Area

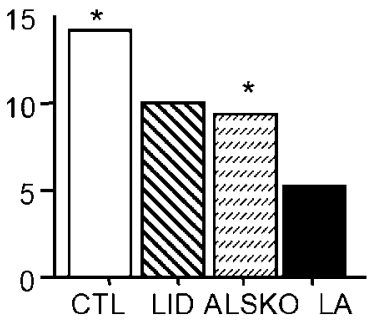

E) Vertebral TbN

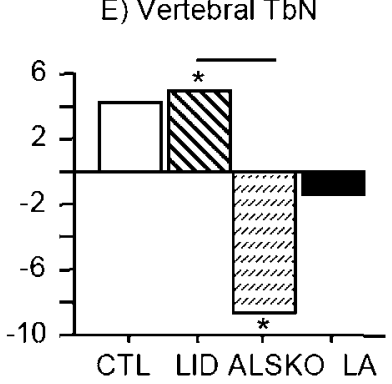

C) Mid-Femoral BATTA

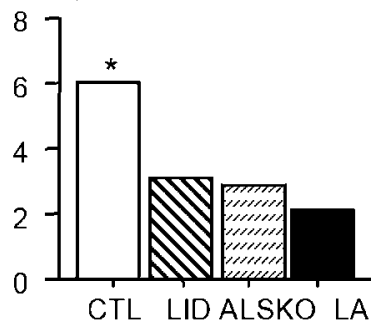

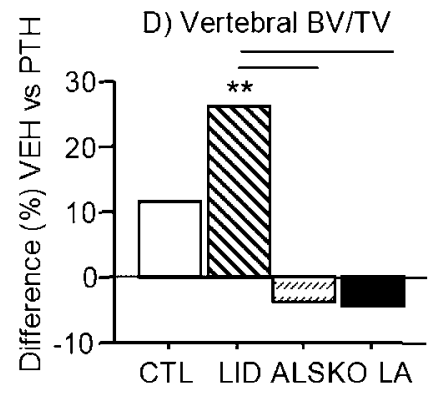

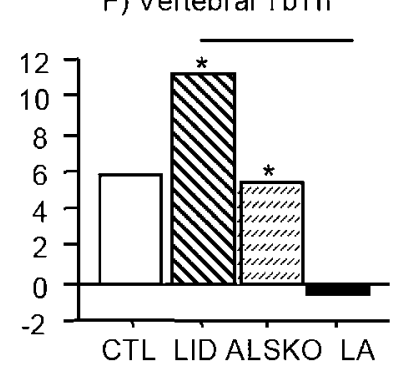

Figure 3 Mean percentage difference in cortical and trabecular bone microarchitecture, assessed by micro-computed tomography, between VEH- and PTH-treated control (CTL), LID, ALSKO and LA mice. (A) Mid-femoral total cross-sectional area, (B) mid-femoral cortical bone area, (C) mid-femoral cortical bone area fraction, (D) vertebral trabecular BV/TV, $(\mathrm{E})$ vertebral trabecular number $(\mathrm{TbN})$, and $(\mathrm{F})$ vertebral trabecular thickness (TbTh). ${ }^{*} P<0 \cdot 05,{ }^{*} P<0 \cdot 01$ for PTH-treated vs VEH-treated. Bars indicate significant $(P<0 \cdot 01)$ differences between groups in the response to PTH.

the presentation of circulating IGF-I (i.e. ternary vs binary complexes) influence the cellular response to intermittent PTH treatment.

\section{Discussion}

In this study we used genetically altered mice (i.e. IGF-I-deficient mice) to examine the influence of the IGF ternary complex on postnatal bone acquisition, as well as the skeletal response to intermittent PTH. Our findings support the thesis that components of the ternary complex (i.e. IGF-I, IGFBP-3 and ALS) modulate bone acquisition and remodeling through compartmentspecific mechanisms (Fig. 4). First, we showed that the cortical skeleton was profoundly affected by changes in complex components of VEH-treated IGF-I-deficient mice. For example, LID had a 15\% decrease, ALSKO had a 30\% decrease, and LA had a $40 \%$ decrease in midfemoral cross-sectional area compared with CTL mice. But these skeletal changes were not reliably predicted by serum IGF-I concentrations. For example, ALSKO mice exhibited smaller periosteal circumferences and less cortical bone area, but actually had higher serum IGF-I levels than LID mice.

In the absence of the ALS, a reduction in circulating IGFBP-3 limits the ability to generate the ternary complex (see Fig. 4). This would lead to a shorter half-life of IGF-I in the circulation, since the unbound IGF-I would be degraded more rapidly. In turn, this could result in less bioactive IGF-I at the tissue level. Alternatively, it is conceivable that the ALS has a direct effect on bone remodeling in addition to its role in binding to IGFBP-3. However, ALS is not expressed in bone or bone marrow stromal cells, hence its effect must be explained by endocrine mechanisms (Ahlborg et al. 2003) (Novartis, http://symatlas.gnf.org/SymAtlas/).

In sharp contrast to cortical bone changes, the trabecular compartment of the distal femur and vertebrae revealed a different pattern. By $\mu \mathrm{CT}$, ALSKO and LA mice had the highest trabecular BV/TV and the greatest number of trabeculae, albeit thinner than CTL mice. The skeletal structure of LA and ALSKO resemble Igf1 null mice with increased trabecular BV/TV (Bikle et al. 2001, Miyakoshi et al. 2001, Bouxsein et al. 2005). Although the mechanism(s) responsible for this increase in Igf1 null mice is not known, two hypotheses have emerged: (1) there is an absence of bone resorption due to a lack of skeletal IGF-I, or (2) there is a marked increase in $\mathrm{GH}$ secretion as a compensation for low circulating IGF-I. With respect to the former scenario, in our current study the number of osteoclasts per bone surface and the eroded surface/ bone surface, a measure of active bone resorption, in VEH-treated ALSKO and LA mice were equal to or 


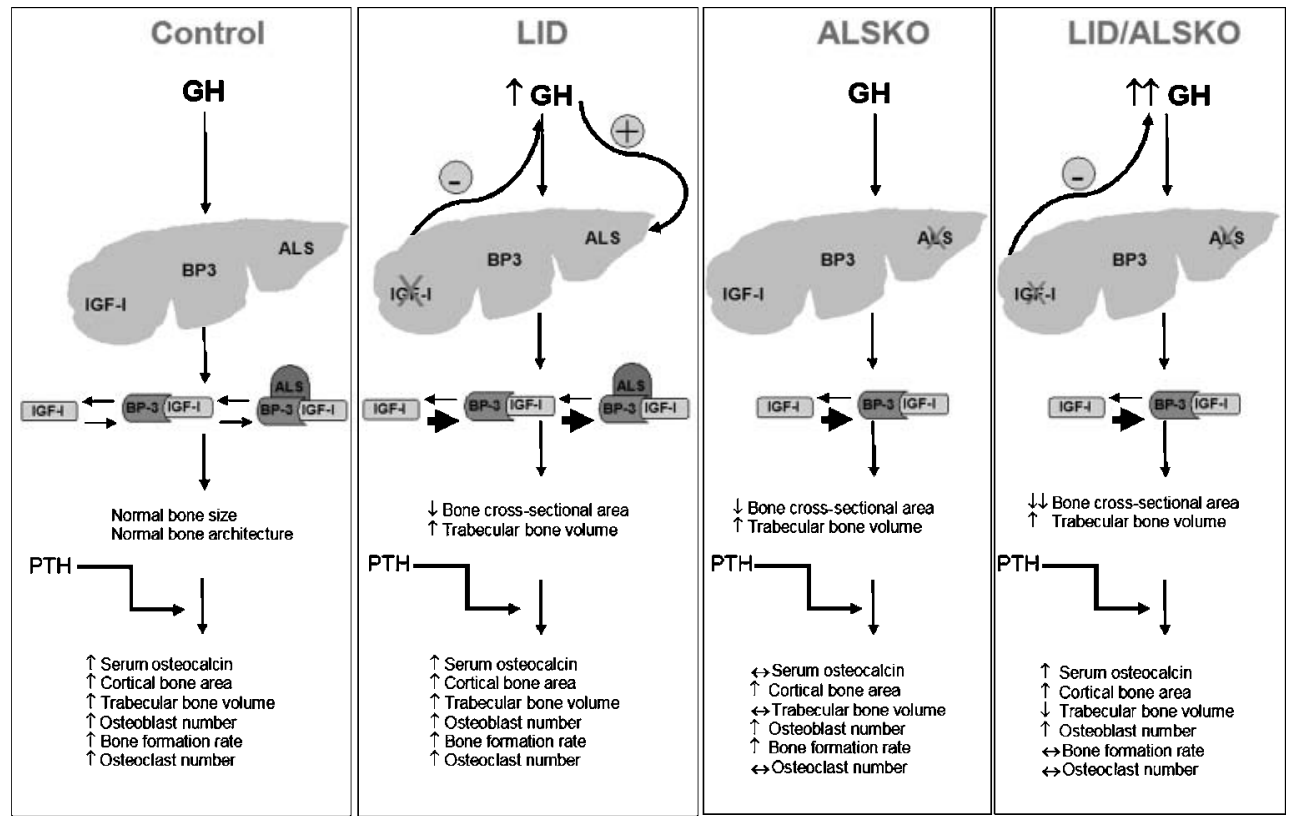

Figure 4 Summary of the skeletal effects resulting from alterations in the IGF-I ternary complex. $\mathrm{BP} 3$, binding protein 3 .

higher than CTL or LID mice. This would exclude the possibility that ALSKO and LA mice have high trabecular $\mathrm{BV} / \mathrm{TV}$ because of less bone resorption at 16 weeks of age. Also, we did not find altered skeletal IGF-I expression in any of the IGF-I-deficient mice, nor in their stromal cells.

The second thesis that a compensatory increase in $\mathrm{GH}$ produces higher trabecular BV/TV deserves closer scrutiny. Another genetically engineered mouse, the insulin receptor substrate (IRS1) null mouse provides some additional insight into this question, since it did not have an anabolic response to PTH despite normal circulating IGF-I concentrations (Yamaguchi et al. 2005). IRS1 null mice have low cortical and trabecular bone mass without a compensatory increase in $\mathrm{GH}$, implying that a rise in GH secretion is essential for maintenance of trabecular bone mass in mice with reduced IGF-I signaling (Yamaguchi et al. 2005). But, ALSKO mice have higher trabecular bone volume fractions than CTL mice, and yet do not show a secondary rise in $\mathrm{GH}$, suggesting another compensatory mechanism could be operative, such as enhanced responsiveness to mechanical loading. However, a limitation in comparing compensatory responses to gene deletion is the genetic background of the lines studied. IRS1 null mice were created on a B6/CBA F1 background, Igf1-/- mice were generated in a CD-1 background and the mice reported in this study were on a mixed background (B6/129/FVBN) (Bikle et al. 2001, Yamaguchi et al. 2005). Hence, further studies will be needed to delineate the functional significance of this paradoxical increase in trabecular bone volume fraction among ALSKO and LA mice.

Another line of evidence that supports a role for the ternary complex in bone turnover is the striking reduction in several parameters related to osteoblast activity in ALSKO mice, without differences in pre-osteoblast IGF-I secretion. This would argue against a deficiency in skeletal IGF-I as the major mechanism responsible for this striking phenotype. On the other hand, LA mice demonstrated significantly greater indices of osteoblast activity (i.e. serum osteocalcin, bone formation rate, mineral apposition rate, and number of osteoblasts per bone perimeter) than ALSKO mice, likely as a result of higher GH concentrations. Overall, the highest rates of bone formation, and the greatest skeletal response to PTH were found in LID mice, who also had the highest ALS concentrations and increased GH (Table 1). Taken together, these data indicate that the ALS plays a vital role in the process of bone formation. That tenet is reinforced by a recent report of an individual with a mutation in the ALS gene resulting in the absence of the circulating IGF ternary complex, and very low areal bone mineral density as measured by dual x-ray absorptiometry (DXA) (Domene et al. 2004).

Previous studies demonstrated that skeletal IGF-I was critical for the full anabolic effect of PTH and for bone mineralization (Bikle et al. 2001, Miyakoshi et al. 2001, Zhang et al. 2002). The most compelling evidence that the ternary complex is also important for optimal responsiveness to PTH is derived from our current study. 
Although PTH modestly increased cortical bone area in all experimental groups, we found the trabecular response at both the vertebrae and distal femur was markedly influenced by genotype. For example, the greatest increase in trabecular bone volume was in LID mice, while ALSKO showed no change and LA mice exhibited a 'catabolic' response to PTH, i.e. a marked loss in trabecular BV/TV. These changes occurred despite a PTH-induced rise in osteoblast number, mineral apposition rate, and bone formation rate in all groups. Conversely, osteoclast activity was only enhanced in those mice that showed an increase in trabecular BV/TV, i.e. wild-type and LID mice.

The sharp contrast in skeletal responsiveness to PTH in the experimental groups is particularly interesting. For example, the 'non-responders' to PTH shared the same common gene deletion of the ALS, and both mutant strains showed a significant impairment in PTH-induced osteoclastic activity. This observation implies that activation of osteoclasts as well as osteoblasts is necessary for a full anabolic response to PTH. This thesis has gained support recently from both mathematical modeling and clinical studies (Black et al. 2003, Finkelstein et al. 2003, Ettinger et al. 2004). But the mechanism responsible for this coupling effect is not clear, although it is conceivable that the defect lies in the signaling between osteoblasts and osteoclasts. One major factor in that process is RANKL, a cytokine produced by stromal cells to induce recruitment of osteoclasts in response to various local and/or endocrine mediators (Lee \& Lorenzo 1999). Interestingly, IGF-I is a potent signal for RANKL activation in marrow stromal cells, suggesting that during states of relative IGF-I insufficiency, osteoclast recruitment by a variety of stimuli may be impaired (Rubin et al. 2002). Whether the absence of the ternary complex in the marrow milieu, or the amount of 'free' IGF-I, reduces RANKL signaling to osteoclasts, particularly with $\mathrm{PTH}$, will require further testing.

In this study we analyzed male littermates on a mixed background, which more accurately reflects genetic heterogeneity in the human population. However, we cannot exclude the possibility that the effects of such a mixed genetic background would differentially affect skeletal acquisition and the anabolic response to PTH. Similarly, there may be gender specificity in terms of the compartmental response to $\mathrm{PTH}$ in mice with specific gene deletions. Notwithstanding those limitations, we have established an essential role for the circulating IGF ternary complex in mediating bone acquisition in the postnatal time period, and the skeletal response to PTH. It is likely that the absence of ALS has a profound effect on the half-life and presentation of IGF-I in the circulation, leading to changes in bone formation and impaired PTH responsiveness. Now that anabolic therapy with PTH is widely available for treating osteoporosis, it would be valuable to determine whether variable presentation of the components of the ternary IGF-I complex in humans could be used to predict skeletal responsiveness to PTH.

\section{Acknowledgements}

We thank Lisa Stadmeyer for performing the histomorphometric measurements. We acknowledge funding from the National Institutes of Health (AR45433 (C J R), AR49265 (M L B), DK42424 (E C), CA100938 (P C) and HD047013 (P C)). The authors declare that there is no conflict of interest that would prejudice the impartiality of this scientific work.

\section{References}

Ahlborg HG, Johnell O, Turner CH, Rannevik G \& Karlsson MK 2003 Bone loss and bone size after menopause. New England Journal of Medicine 349 327-334.

Bikle D, Majumdar S, Laib A, Powell-Braxton L, Rosen C, Beamer W, Nauman E, Leary C \& Halloran B 2001 The skeletal structure of insulin-like growth factor I-deficient mice. Journal of Bone Mineral Research $162320-2329$.

Bikle DD, Sakata T, Leary C, Elalieh H, Ginzinger D, Rosen CJ, Beamer W, Majumdar S \& Halloran BP 2002 Insulin-like growth factor $\mathrm{I}$ is required for the anabolic actions of parathyroid hormone on mouse bone. Journal of Bone Mineral Research 17 1570-1578.

Black DM, Greenspan SL, Ensrud KE, Palermo L, McGowan JA, Lang TF, Garnero P, Bouxsein ML, Bilezikian JP \& Rosen CJ 2003 The effects of parathyroid hormone and alendronate alone or in combination in postmenopausal osteoporosis. New England Journal of Medicine 349 1207-1215.

Bouxsein ML, Pierroz DD, Glatt V, Goddard DS, Cavat F, Rizzoli R \& Ferrari SL 2005 Beta-arrestin2 regulates the differential response of cortical and trabecular bone to intermittent PTH in female mice. Journal of Bone Mineral Research 20 635-643.

Calvi LM, Adams GB, Weibrecht KW, Weber JM, Olson DP, Knight MC, Martin RP, Schipani E, Divieti P, Bringhurst FR et al. 2003 Osteoblastic cells regulate the haematopoietic stem cell niche. Nature 425 841-846.

Canalis E, Centrella M, Burch W \& McCarthy TL 1989 Insulin-like growth factor I mediates selective anabolic effects of parathyroid hormone in bone cultures. Journal of Clinical Investigations 83 60-65.

Domene HM, Bengolea SV, Martinez AS, Ropelato MG, Pennisi P, Scaglia P, Heinrich JJ \& Jasper HG 2004 Deficiency of the circulating insulin-like growth factor system associated with inactivation of the acid-labile subunit gene. New England Journal of Medicine 350 570-577.

Ettinger B, San Martin J, Crans G \& Pavo I 2004 Differential effects of teriparatide on BMD after treatment with raloxifene or alendronate. Journal of Bone Mineral Research 19 745-751.

Finkelstein JS, Hayes A, Hunzelman JL, Wyland JJ, Lee H \& Neer RM 2003 The effects of parathyroid hormone, alendronate, or both in men with osteoporosis. New England Journal of Medicine 349 1216-1226.

Gamero P, Sornay-Rendu E \& Delmas PD 2000 Low serum IGF-I and occurrence of osteoporotic fractures in postmenopausal women. Lancet 355 898-899.

Hildebrand T \& Ruegsegger P 1997 A new method for the model independent assessment of thickness in three-dimensional images. Journal of Microscopy 185 67-75.

Hurley MM, Tetradis S, Huang YF, Hock J, Kream BE, Raisz LG \& Sabbieti MG 1999 Parathyroid hormone regulates the expression of fibroblast growth factor-2 mRNA and fibroblast growth factor receptor mRNA in osteoblastic cells. Journal of Bone Mineral Research 14 776-783. 
Jilka RL, Weinstein RS, Bellido T, Roberson P, Parfitt AM \& Manolagas SC 1999 Increased bone formation by prevention of osteoblast apoptosis with parathyroid hormone. Journal of Clinical Investigations 104 439-446.

Laib A, Hildebrand T, Hauselmann HJ \& Ruegsegger P 1997 Ridge number density: a new parameter for in vivo bone structure analysis. Bone 21 541-546.

Langlois JA, Rosen CJ, Visser M, Hannan MT, Harris T, Wilson PW \& Kiel DP 1998 Association between insulin-like growth factor I and bone mineral density in older women and men: the Framingham Heart Study. Journal of Clinical Endocrinology and Metabolism 83 4257-4262.

Lee SK \& Lorenzo JA 1999 Parathyroid hormone stimulates TRANCE and inhibits osteoprotegerin messenger ribonucleic acid expression in murine bone marrow cultures: correlation with osteoclast-like cell formation. Endocrinology 140 3552-3561.

Leong SR, Baxter RC, Camerato T, Dai J \& Wood WI 1992 Structure and functional expression of the acid-labile subunit of the insulin-like growth factor-binding protein complex. Molecular Endocrinology 6 870-876.

LeRoith D, Bondy C, Yakar S, Liu A \& Butler A 2001 The somatomedin hypothesis: endocrine reviews. Endocrine Reviews 22 53-74.

McCarthy TL, Centrella M \& Canalis E 1989 Parathyroid hormone enhances the transcript and polypeptide levels of insulin-like growth factor I in osteoblast-enriched cultures from fetal rat bone. Endocrinology 124 1247-1253.

Miyakoshi N, Kasukawa Y, Linkhart TA, Baylink DJ \& Mohan S 2001 Evidence that anabolic effects of PTH on bone require IGF-I in growing mice. Endocrinology 142 4349-4356.

Mochizuki H, Hakeda Y, Wakatsuki N, Usui N, Akashi S, Sato T, Tanaka K \& Kumegawa M 1992 Insulin-like growth factor-I supports formation and activation of osteoclasts. Endocrinology 131 1075-1080.

Neer RM, Arnaud CD, Zanchetta JR, Prince R, Gaich GA, Reginster JY, Hodsman AB, Eriksen EF, Ish-Shalom S, Genant HK et al. 2001 Effect of parathyroid hormone (1-34) on fractures and bone mineral density in postmenopausal women with osteoporosis. New England Journal of Medicine 344 1434-1441.

Novartis http://symatlas.gnf.org/SymAtlas/ Novartis ALS.

Parfitt AM, Drezner MK, Glorieux FH, Kanis JA, Malluche H, Meunier PJ, Ott SM \& Recker RR 1987 Bone histomorphometry: standardization of nomenclature, symbols, and units. Report of the ASBMR Histomorphometry Nomenclature Committee. Journal of Bone Mineral Research 2 595-610.

Qin L, Qiu P, Wang L, Li X, Swarthout JT, Soteropoulos P, Tolias P \& Partridge NC 2003 Gene expression profiles and transcription factors involved in parathyroid hormone signaling in osteoblasts revealed by microarray and bioinformatics. Journal of Biological Chemistry 278 19723-19731.

Rosen CJ, Ackert-Bicknell CL, Adamo ML, Shultz KL, Rubin J, Donahue LR, Horton LG, Delahunty KM, Beamer WG, Sipos J et al. 2004 Congenic mice with low serum IGF-I have increased body fat, reduced bone mineral density, and an altered osteoblast differentiation program. Bone 35 1046-1058.

Rosen CJ, Ackert-Bicknell C, Beamer WG, Nelson T, Adamo M, Cohen P, Bouxsein ML \& Horowitz MC 2005 Allelic differences in a quantitative trait locus affecting insulin-like growth factor-I impact skeletal acquisition and body composition. Pediatric Nephrology 20 255-260.

Rubin J, Ackert-Bicknell CL, Zhu L, Fan X, Murphy TC, Nanes MS, Marcus R, Holloway L, Beamer WG \& Rosen CJ 2002 IGF-I regulates osteoprotegerin $(\mathrm{OPG})$ and receptor activator of nuclear factor-kappaB ligand in vitro and OPG in vivo. Journal of Clinical Endocrinology and Metabolism 87 4273-4279.

Salmon WD \& Daughaday WH 1957 A hormonally controlled serum factor which stimulates sulfate incorporation by cartilage in vitro. Journal of Laboratory and Clinical Medicine 49 825-836.

Sellmeyer DE, Palermo L, Bouxsein ML, Bilezikian J, Greenspan S, Ensrud K, Black D \& Rosen CJ 2004 Heterogeneity in skeletal response to full-length parathyroid hormone (PTH). Journal of Bone and Mineral Research 19 S96.

Yakar S, Liu JL, Stannard B, Butler A, Accili D, Sauer B \& LeRoith D 1999 Normal growth and development in the absence of hepatic insulin-like growth factor I. PNAS 96 7324-7329.

Yakar S, Rosen CJ, Beamer WG, Ackert-Bicknell CL, Wu Y, Liu JL, Ooi GT, Setser J, Frystyk J, Boisclair YR et al. 2002a Circulating levels of IGF-I directly regulate bone growth and density. Journal of Clinical Investigations $110771-781$.

Yakar S, Wu Y, Setser J \& Rosen CJ $2002 b$ The role of circulating IGF-I: lessons from human and animal models. Endocrine 19 239-248.

Yamaguchi M, Ogata N, Shinoda Y, Akune T, Kamekura S, Terauchi Y, Kadowaki T, Hoshi K, Chung UI, Nakamura K et al. 2005 Insulin receptor substrate-1 is required for bone anabolic function of parathyroid hormone in mice. Endocrinology $1462620-2628$

Zhang M, Xuan S, Bouxsein ML, von Stechow D, Akeno N, Faugere MC, Malluche H, Zhao G, Rosen CJ, Efstratiadis A et al. 2002 Osteoblast-specific knockout of the insulin-like growth factor (IGF) receptor gene reveals an essential role of IGF signaling in bone matrix mineralization. Journal of Biological Chemistry 277 44005-44012.

Zhao G, Monier-Faugere MC, Langub MC, Geng Z, Nakayama T, Pike JW, Chernausek SD, Rosen CJ, Donahue LR, Malluche $\mathrm{HH}$ et al. 2000 Targeted overexpression of insulin-like growth factor I to osteoblasts of transgenic mice: increased trabecular bone volume without increased osteoblast proliferation. Endocrinology 141 2674-2682.

Received in final form 28 December 2005

Accepted 1 February 2006

Made available online as an Accepted Preprint 2 February 2006 